\title{
Attenuation of virus-induced airway dysfunction in rats treated with imiquimod
}

\author{
J.R. Stokes*, R.L. Sorkness**, M.R. Kaplan*, W.L. Castleman+, M.A. Tomai++, \\ R.L. Miller++, R.F. Lemanske Jr*
}

Attenuation of virus-induced airway dysfunction in rats treated with imiquimod. J.R. Stokes, R.L Sorkness, M.R. Kaplan, W.L. Castleman, M.A. Tomai, R.L. Miller, R.F. Lemanske Jr. @ERS Journals Ltd 1998.

ABSTRACT: Viral respiratory infections cause acute airway abnormalities consisting of inflammation and physiological dysfunction in both animals and humans. It is likely that inflammatory cell products, such as cytokines, contribute substantially to viral-induced airway dysfunction. We hypothesized that imiquimod, an immune response enhancing agent that induces interferon- $\alpha$, would attenuate the development of airway dysfunction during acute viral illness in rats.

Adult Brown Norway rats were inoculated with parainfluenza type 1 (Sendai) virus or sterile vehicle, and treated with either imiquimod or water. Respiratory system resistance $(R \mathrm{rs})$, arterial oxygen tension $\left(\mathrm{Pa}_{\mathrm{a}} \mathrm{O}_{2}\right)$, lung viral titres and bronchoalveolar lavage (BAL) leucocyte counts were measured in anaesthetized, paralysed, ventilated rats.

Virus-infected, water-treated rats had a significant decrease in $\mathrm{Pa}_{\mathrm{a}} \mathrm{O}_{2}$ and had significant increases in leucocyte count and $R$ rs when compared to both the virusinfected, imiquimod-treated, $\left(P \mathrm{a}_{2}, \mathrm{O}_{2}, \mathrm{p}=0.03\right.$; leucocyte count, $\mathrm{p}=0.02$; and $R \mathrm{rs}, \mathrm{p}=$ $0.009)$ and noninfected, water-treated rats $\left(P a, O_{2}, p=0.007\right.$; leucocyte count, $p=0.001$; and $R \mathrm{rs}, \mathrm{p}=0.01)$. In addition, imiquimod suppressed BAL eosinophils in both virusinfected $(p=0.02)$ and noninfected $(p=0.001)$ groups, and lowered overall virus titres $(\mathbf{p}=\mathbf{0 . 0 3})$.

Thus, both virus-induced airway inflammation and physiological dysfunction were attenuated significantly by imiquimod treatment in this animal model. By further delineating mechanisms by which infections induce airway dysfunction in animal models, more specific pharmacological interventions can be developed for the treatment of virus-induced asthma.

Eur Respir J 1998; 11: 324-329.
*Division of Allergy and Immunology, and **School of Pharmacy, Depts of Pediatrics and Medicine, University of Wisconsin, USA. +University of Florida, Dept of Pathobiology, and +3M Pharmaceuticals, St Paul, Minnesota, USA.

Correspondence: R.L. Sorkness,

University of Wisconsin Clinical Science Center

600 Highland Ave, H6/367

Madison, WI

USA

Fax: 16082633104

Keywords: Asthma

cytokines

interferon- $\alpha$

parainfluenza

Sendai virus

Received: April 91997

Accepted after revision October 31997

This study was supported by 3M Pharmaceuticals and the National Institute of Health (NIH) AI-34891
Respiratory viral infections, such as bronchiolitis, cause acute airway obstruction and hyperresponsiveness in persons with otherwise normal airways [1], and exacerbate airway dysfunction in persons with asthma $[1,2]$. One of the prominent features of viral respiratory infections is airway inflammation [2], including phagocytic cells (macrophages, neutrophils) and specific antigen recognition cells (B-lymphocytes, T-lymphocytes) and cellular products such as immunoglobulins and cytokines [3]. Cytokines play a pivotal role in co-ordinating the inflammatory responses, but may also contribute to virus-induced airway dysfunction.

The imidazoquinolinamine derivative, imiquimod (R-837, S-26308), has been shown to be a potent immune response modifier in both animal and human subjects, as well as an effective antitumour and antiviral agent in animal models. Guinea-pigs treated with imiquimod either prophylactically or therapeutically can be protected from primary and recurrent infections of herpes simplex virus [4-7]. An antiviral effect has also been reported for imiquimodtreated guinea-pigs with cytomegalovirus (CMV) [8], and in mice with arbovirus infection [9]. As imiquimod has no in vitro anti-herpes simplex virus (HSV) activity [6], its antiviral or antitumour activity in this circumstance is presumed to be due to induction of cytokines such as interferon$\alpha$ [10]. In this regard, imiquimod induces interferon- $\alpha$ formation in a number of species including guinea-pigs, mice, rats, monkeys and humans [5, 11-17]. Furthermore, it increases synthesis of interleukin (IL)-6 and tumour necrosis factor (TNF)- $\alpha$ [13] in mice as well as from human peripheral blood mononuclear cells in vitro $[11,12,14,15]$.

In previous reports $[18,19]$ we have demonstrated that parainfluenza type 1 infection in rats produces virus-induced airway dysfunction and inflammation with many biological and physiological features that parallel those seen in humans. To determine the potential efficacy of imiquimod as a treatment for virus-induced airway dysfunction, we administered this drug before and during acute viral respiratory illness in this rat model, and measured effects on pulmonary physiology and viral replication. Our hypothesis was that imiquimod treatment would significantly attenuate the development of airway dysfunction during acute viral illness in Brown Norway rats. 


\section{Methods}

\section{Experimental design}

All procedures were approved by the Animal Care and Use Committee of the University of Wisconsin. Adult male Brown Norway rats, seronegative for common rodent pathogens (Charles River Laboratories, Kingston, NY, USA), were used for the study.

Rats were treated with either imiquimod (3M Pharmaceuticals, St Paul, Minnesota, USA), 1-(2-methylpropyl)1H-imidazo-[4,5-c] quinolin-4-amine $\left(30 \mathrm{mg} \cdot \mathrm{kg}^{-1}\right)$, a dose that in mice appears to produce peak interferon levels with minimal toxicity [13], or an equal volume of sterile water via orogastric tube. Dosing was performed 1 day prior to in-oculation (day -1) and three days postinoculation (day 3 ). Both imiquimod and control rats were divided further into study groups that were either virus- or sham-inoculated (day 0) as follows: virus-inoculated/imiquimod-treated (VI; $n=18)$; virus-inoculated/water-treated (VW; $n=18$ ); sham-inoculated/imiquimod-treated (SI; $n=8)$; and shaminoculated/water-treated (SW; $\mathrm{n}=8$ ) (fig. 1). Rats from each treatment group were used for terminal studies on postinoculation days 1-7. Studies included bronchoalveolar lavage (BAL) and serum for interferon levels (days 17), lung viral titres (days 3-7), and pulmonary physiology (days 4-7). All measurements were conducted by investigators blinded to drug treatment group assignments.

\section{Inoculation}

Rats were exposed to an aerosol containing parainfluenza type 1 (Sendai) virus strain P3193 on day 0 by use of a Glas-Col Aerosol Exposure Apparatus (Glas-Col, Terre Haute, IN, USA) as described previously [19]. Noninfected rats were sham-inoculated with aerosolized chorioallantoic fluid in a similar manner. Infected and noninfected rats were housed in micro-isolator cages under identical conditions, and studied at different times to ensure that noninfected rats had no exposure to virus.

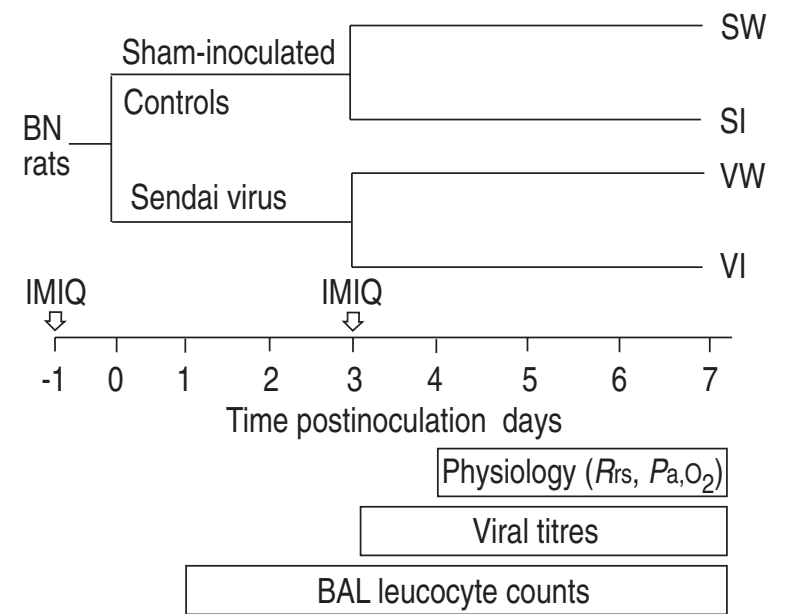

Fig. 1. - Study design. Brown Norway (BN) rats were either sham- or virus-inoculated at day 0 . Imiquimod (IMIG; $30 \mathrm{mg} \cdot \mathrm{kg}^{-1}$ ) or water was given orally 1 day prior, and 3 days after inoculation. SW: sham/water; SI: sham/imiquimod; VW: virus/water; VI: virus/Imiquimod; BAL: bronchoalveolar lavage; $R \mathrm{rs}$ : respiratory system resistance; $P \mathrm{a}_{2} \mathrm{O}_{2}$ : arterial oxygen tension.

\section{Physiology measurements}

Rats were anaesthetized with i.p. ketamine $\left(50 \mathrm{mg} \cdot \mathrm{kg}^{-1}\right.$; Parke-Davis/Warner-Lambert, Morris Plains, NJ, USA) and xylazine ( $5 \mathrm{mg} \cdot \mathrm{kg}^{-1}$; Sigma Chemical, St Louis, MO, USA). After anaesthesia, cannulas were placed in the trachea, femoral vein, and femoral artery. The animals were placed supine in a constant-pressure rodent plethysmograph, pretreated with propranolol $\left(2 \mathrm{mg} \cdot \mathrm{kg}^{-1}\right.$ i.v.; Sigma Chemical), paralysed with succinylcholine chloride (4 $\mathrm{mg} \cdot \mathrm{kg}^{-1}$ i.v.; Sigma Chemical), and mechanically ventilated at 80 breaths min $^{-1}$ with $2.5 \mathrm{cmH}_{2} \mathrm{O}$ positive end-expiratory pressure and a tidal volume adjusted to maintain a $P \mathrm{a}, \mathrm{CO}_{2}$ of $4.7-5.3 \mathrm{kPa}(35-45 \mathrm{mmHg})$. Arterial blood was obtained for blood gas analysis after 10 min of mechanical ventilation as described previously [20]. Lungs were inflated to a pressure of $30 \mathrm{cmH}_{2} \mathrm{O}$ each minute to prevent atelectasis, and secretions were suctioned from the airways as needed.

Resistance was determined from inflation pressure and the plethysmograph flow signal by the isovolume method (model 6 Pulmonary Analyzer; Buxco Electronics, Sharon, CT, USA) as described previously [21]. Respiratory system resistance $(R \mathrm{rs})$ was obtained from the computed resistance by subtracting the flow-specific resistance of the tracheal cannula and its connector.

After physiological measurements, the rats were sacrificed by exsanguination then given an air embolus to assure circulatory arrest. The thoracic cavity was exposed, the left main bronchus was tied, and the left lung was removed, frozen in liquid $\mathrm{N}_{2}$, and stored at $-80^{\circ} \mathrm{C}$. Viral titres were performed on lung homogenates by inoculation into Madin-Darby bovine kidney cells [18]. BAL was performed by inflating the right lung to total lung capacity with Hanks' balanced salt solution (without calcium and magnesium) and then draining it by gravity, for a total of five exchanges. The lavage fluid was centrifuged and the cell pellet was resuspended in $1 \mathrm{~mL}$ of buffer. Total BAL cell counts were measured with a Hemo-W cell counter (Coulter Electronics, Hialeah, FL, USA). Leucocyte differential counts were obtained from 200 BAL cells on a Cytospin (Shandon Lipshaw Inc., Pittsburgh, PA, USA) slide stained with Diff-Quik (Baxter Healthcare Corp., Miami, FL, USA).

\section{Interferon assays}

Interferon assays were performed by $3 \mathrm{M}$ Pharmaceuticals using a method described previously [13, 22]. Serum samples were obtained either within $5 \mathrm{~h}$ of an imiquimod dose or at 1-4 days after the dose. In 12 rats it was possible to obtain serum samples at more than one time point in the first $5 \mathrm{~h}$ after the dose, so each sample is reported individually.

\section{Statistical analysis}

Statistical analysis was performed using Systat version 5.03 software (Systat Inc., Evanston, IL, USA). KruskalWallis one-way analysis of variance (ANOVA) was used to detect differences among the four study groups. For variables having significant ANOVA, post hoc planned pairwise comparisons were conducted with the Mann-Whitney test. Changes in body weight were evaluated with repeated measures ANOVA, using baseline weight as a covariate. 


\section{Results}

\section{Viral effects}

There was an increase in total BAL inflammatory cells due to viral infection, as shown by differences between the infected (VW) and noninfected control (SW) groups (fig. 2). The inflammatory response consisted of increased numbers of macrophages $(\mathrm{p}=0.002)$, lymphocytes $(\mathrm{p}=$ $0.04)$, and neutrophils ( $\mathrm{p}=0.0007)$ (data not shown). Respiratory viral illness also produced airway obstruction, as measured by differences in pulmonary physiology in the infected (VW) compared to the noninfected (SW) control groups, infected rats had an increase in $R$ rs (fig. 3) and a decrease in oxygenation (fig. 4).

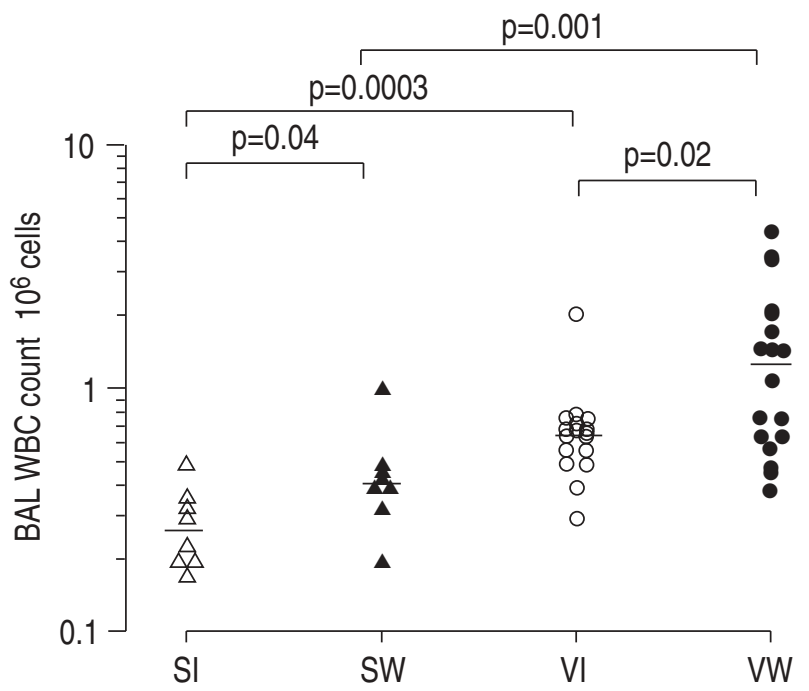

Fig. 2. - Leucocytes in bronchoalveolar lavage (BAL) from virus infected and sham-inoculated control rats treated with imiquimod or water. Group medians are indicated by horizontal bars. The p-values indicate significant differences between groups. Values are pooled data from days 1-7 postinoculation. SI: sham-inoculated, imiquimod treated; SW: sham-inoculated, water treated; VI: virus-infected, imiquimod treated; VW: virus-infected, water treated; WBC: white blood cell.

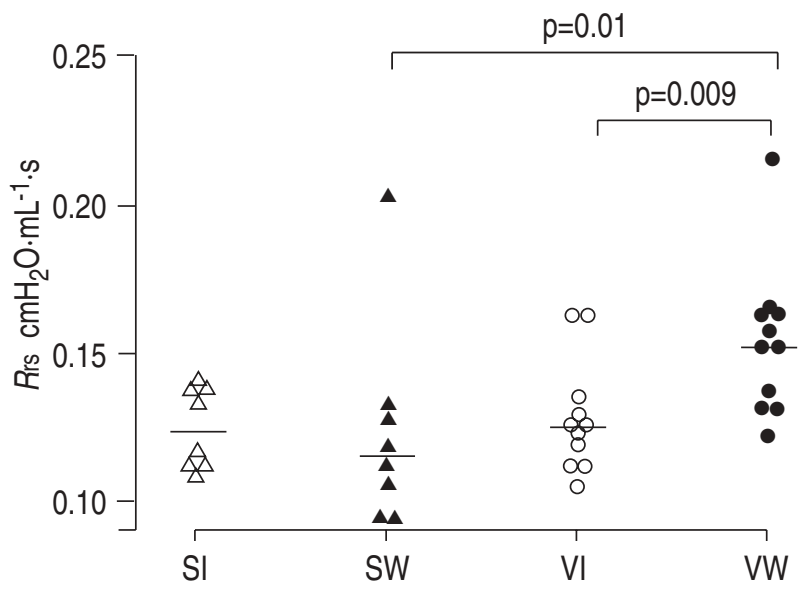

Fig. 3. - Respiratory system resistance $(R \mathrm{rs})$ in virus-infected and sham-inoculated control rats treated with imiquimod or water. Group medians are indicated by horizontal bars. The p-values indicate significant differences between groups. Values are pooled data from days 4-7 postinoculation. For definitions see legend to figure 2.

\section{Imiquimod effects}

Viral titres. Viral titres were markedly different in the virus-infected groups on postinoculation day 3, the day of the postinoculation drug dose (second dose of the two administered). The imiquimod treated rats had no virus recovered from their lungs, while water-treated rats all had high viral titres ( $p=0.04$, fig. 5). The imiquimod group continued to have lower titres of virus on days 4-5 ( $\mathrm{p}=0.02)$, but did not differ significantly from untreated rats on days $6-7$, when the untreated rats also experienced a reduction in viral titres (fig. 5). Overall, a significant difference between the water and imiquimod groups was detected when titres for all days were combined $(\mathrm{p}=0.03)$.

Inflammation. As illustrated in figure 2, water-treated virus-infected rats had an increase in their BAL leucocyte counts (VW versus $\mathrm{SW}, \mathrm{p}=0.001$ ) which was significantly

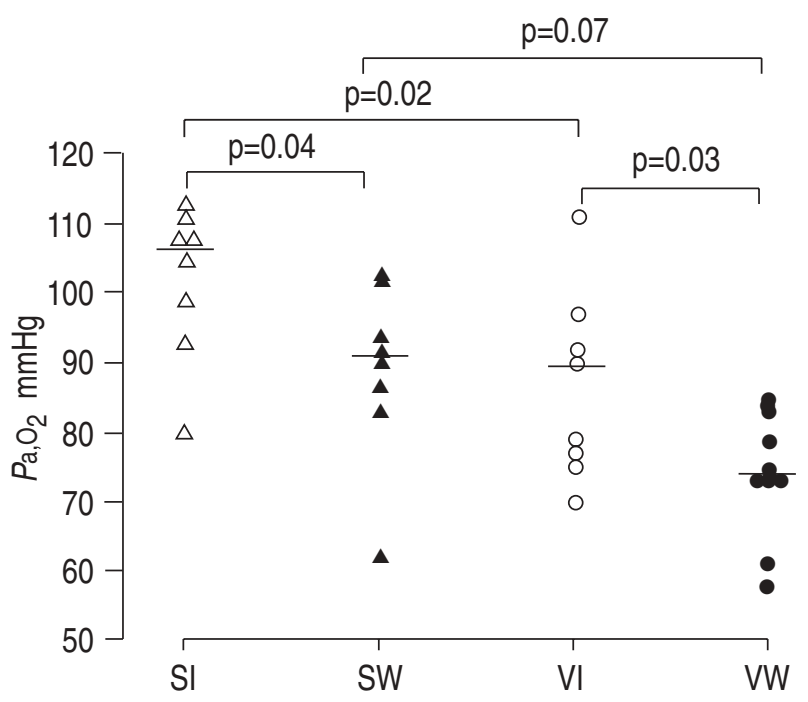

Fig. 4. - Eucapnic arterial oxygen tension $\left(\mathrm{Pa}_{\mathrm{a}} \mathrm{O}_{2}\right)$ in virus-infected and sham-inoculated control rats treated with imiquimod or water. Group medians are indicated by horizontal bars. The p-values indicate significant differences between groups. the values are pooled data from days 4-7 postinoculation. For definitions see legend to figure $2.1 \mathrm{mmHg}=$ $0.133 \mathrm{kPa}$.

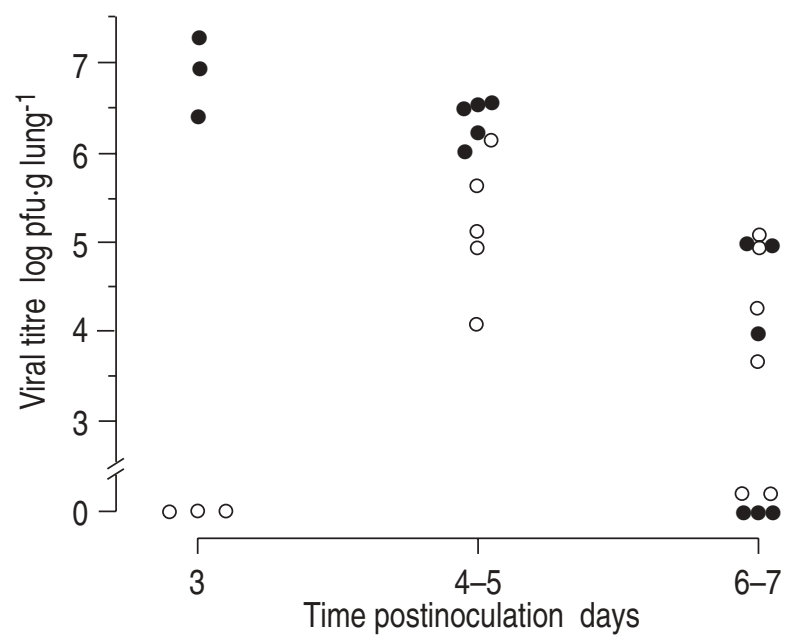

Fig. 5. - Viral titres from Sendai virus-infected rats treated with either imiquimod or water. The p-value for all days combined was 0.03. $\mathrm{O}$ : imiquimod-treated; ๑: water-treated. pfu: plaque-forming units. 
attenuated following imiquimod treatment (VW versus VI, $\mathrm{p}=0.02$ ). Virus-infected rats demonstrated an early substantial increase in the percentage of neutrophils in BAL, which was attenuated following imiquimod treatment. A trend for a later increase in the percentage of lymphocytes was noted following virus infection. Although there was no discernable effect of acute viral infection on BAL eosinophils, there was a potent suppressive effect of imiquimod on BAL eosinophils in both infected and noninfected rats (fig. 6).

Physiology. Virus-induced changes in pulmonary physiology were also attenuated by imiquimod treatment (figs. 3 and 4). In infected rats, Rrs was significantly reduced by treatment with imiquimod (VI versus VW, $\mathrm{p}=0.009$ ) while oxygenation was increased (VI versus $\mathrm{VW}, \mathrm{p}=0.03$ ). Imiquimod treatment in the noninfected rats also improved oxygenation when compared with the water treated group (SI versus SW, fig. 4).

Interferon levels. Interferon levels were measured in both infected and noninfected rats treated with imiquimod (VI and SI), and no significant difference was noted. Peak levels of interferon were detected 1.6-4.5 h after dosing, with no detectable levels found before this period or greater than $24 \mathrm{~h}$ after dosing in all rats treated with imiquimod. Of the 40 serum samples obtained from rats not treated with imiquimod (21 infected, 19 noninfected) only two (both infected) had detectable interferon levels; the levels were at the low end of the sensitivity range (200 and 130 $\left.\mathrm{U} \cdot \mathrm{mL}^{-1}\right)$ and detected on day 4 after viral inoculation. In imiquimod treated animals, a significant difference was noted compared to water-treated animals for samples obtained $1.5-5 \mathrm{~h}$ after treatment $(\mathrm{p}=0.005)$. In samples obtained less than $1.5 \mathrm{~h}$ and greater than $5 \mathrm{~h}$ after treatment, no difference was noted between the water and imiquimod treated groups.

Metabolic effects. All rats treated with imiquimod had transient interruption of weight gain after the doses given

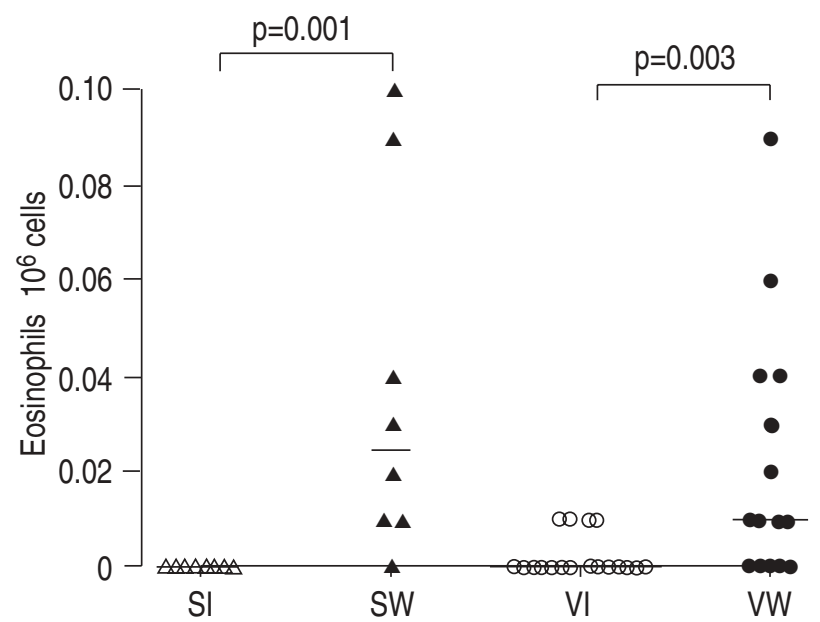

Fig. 6. - Total eosinophil counts in BAL from virus-infected and shaminoculated control rats treated with imiquimod or water. Group medians are indicated by horizontal bars. the p-values indicate significant differences between groups. Values are pooled data from days 1-7 postinoculation. For definitions, see legend to figure 2.

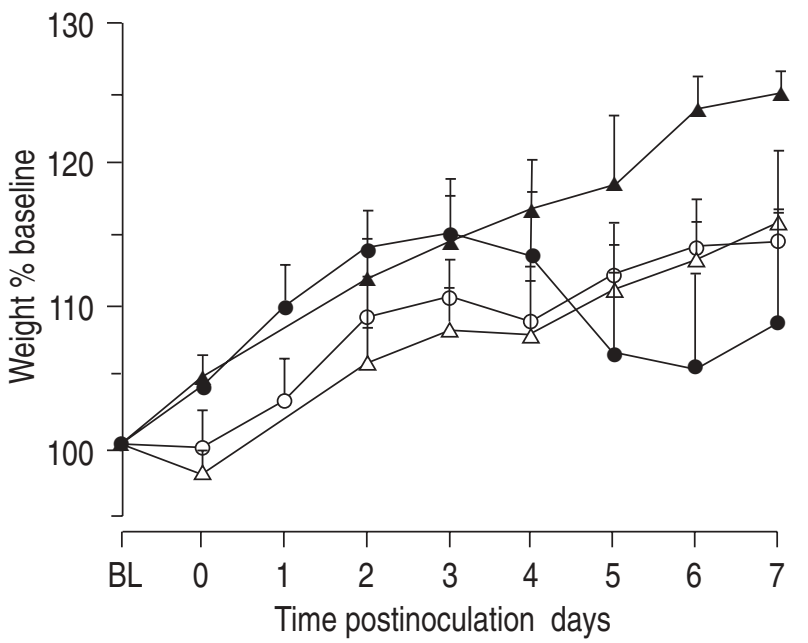

Fig. 7. - Weight changes from baseline in virus-infected and shaminoculated rats treated with imiquimod or water. Values are presented as mean \pm S D . ๑: VW;O : VI; $\Delta$ : SW; $\triangle$ : SI. BL: baseline. For further definitions see legend to figure 1 .

on both day $-1(\mathrm{p}<0.0001)$ and day $3(\mathrm{p}=0.004)$, but the overall weight gain was constant (fig. 7). Virus infection also had a significant effect on weight on days $3-4(\mathrm{p}=$ $0.004)$ and on day 5 there was a significant difference $(\mathrm{p}=0.0001)$ between SW and VW rats. A significant difference in weight was also noted on day 5 between SI and $\mathrm{SW}$ rats $(\mathrm{p}=0.026)$ and VI and VW rats $(\mathrm{p}=0.021)$. No difference was noted between SI and VI animals at this time point $(\mathrm{p}>0.7)$.

\section{Discussion}

The present experiments confirm our previous findings that Sendai virus infections in rats produce physiological dysfunction [21, 23], airway inflammation [23] and increases in lung viral titres [18]. Furthermore, we have demonstrated that imiquimod treatment attenuates viral titres, virus-induced airway dysfunction and airway inflammation in this rat model.

The present findings are probably the result of a significant tissue antiviral effect of imiquimod. We analysed viral titres in water and imiquimod-treated rats at day 3 postinoculation, the day of imiquimod dosing, days 4-5 (when the titre typically peaks) and on days 6-7 (when titres typically decline). Overall, peak viral titres were delayed and reduced in the imiquimod treated rats. At day 3 postinoculation, the water-treated group achieved the maximal viral titre recorded during the evaluation period, while no titres were detected in the imiquimod group. A possible explanation for this finding is that cytokines reduced viral replication in the airway to such an extent that virus at day 3 was undetectable. The finding is similar to previous studies, in which guinea-pigs treated with imiquimod $24 \mathrm{~h}$ prior to CMV infection had a low rate of viraemia at day 3 postinoculation, but peaked by day 5 [8]. Imiquimod has been shown to have antiviral effects in other animal models of virus infection $[4,6,7]$. In the present study, some of the imiquimod-treated rats had virus present on days 6-7, but in subsequent experiments performed in our laboratories, rats treated with either water or imiquimod had undetectable levels of virus by day 10 
postinoculation [24]. Based on these initial observations, it would be interesting to undertake a more comprehensive evaluation of the viral titre levels from day 1 to day 10 postinoculation in this model.

To evaluate the mechanisms by which imiquimod exerted its significant antiviral effects, we focused our cytokine evaluation on the effects of imiquimod on interferon levels based on previous reports [5, 10-17]. We noted that levels of interferon were increased for several hours after dosing, but were not detectable before $1.5 \mathrm{~h}$ or after $24 \mathrm{~h}$. In rats not treated with imiquimod, no interferon levels were detected within $24 \mathrm{~h}$ after dosing with water (control). Previous observations have found that greater than $97 \%$ of the total serum interferon induced by imiquimod was interferon- $\alpha[12,13,15,16]$.

The benefits of treatment with imiquimod, however, are not explained fully by the ability of the drug to augment interferon- $\alpha$ production. For example, antibody to interferon has been shown to only partially inhibit the benefit of imiquimod in mouse models of virus infection [25] or in mouse models of tumours [10]. In previous studies in rats, imiquimod stimulated production of both interferon$\alpha$ and TNF [13]. In mice and rats, imiquimod increased serum levels of TNF- $\alpha$ with peak levels seen at 1-2 h; peak levels of interferon- $\alpha$ and IL- 6 were seen $2-3 \mathrm{~h}$ after dosing [13]. Using a variety of in vitro systems, imiquimod has been found to increase levels of interferon 300500 fold, while other cytokines (TNF- $\alpha$, IL-6, and IL-8) increased by imiquimod were increased to a maximum of nearly 40 fold $[11,15]$.

Based on these reported observations, it is possible that the decreased viral titres observed in animals treated with imiquimod may have been mediated through interferon- $\alpha$ interacting with CD4+ T-cells. Proposed subsets of these T-cells include the type 1 T-helper (Th1) cells producing predominantly IL- 2 , interferon- $\gamma$, and TNF- $\beta$; and the type 2 T-helper (Th2) cells preferentially producing IL-4, IL-5 and IL-10 [26]. Interferon- $\alpha$ has been shown to enhance interferon- $\gamma$ production by Th1 cells $[27,28]$, while inhibiting Th2 cytokine production [28]. Interferon- $\alpha$ may favour the predominance of a Th1 response by inducing interferon- $\gamma$ and inhibiting IL-4 production. Indeed, interferon- $\alpha$ has been found to inhibit IL-4 messenger ribonucleic acid (mRNA) levels and immunoglobulin E (IgE) production in mice [29] and moreover, anti-IL-4 treatment in mice infected with RSV modulates cytokine production, reduces illness and increases cytotoxic T-lymphocyte activity [30].

In addition to its effects on viral titres and interferon$\alpha$ levels, imiquimod treatment influenced BAL leucocyte numbers in both the infected and noninfected animals. The decrease in the background inflammation that is typically present in adult Brown Norway rats could be a drug effect consistent with one of imiquimod's postulated mechanisms. This decrease in background inflammation may be the reason that oxygenation improved in the noninfected animals treated with imiquimod.

Of particular interest was the effect of imiquimod on populations of polymorphonuclear leucocytes. The diminished numbers seen following treatment are probably not related to a direct effect of interferon- $\alpha$ on cellular chemotaxis [31]. In both infected and noninfected rats treated with imiquimod, BAL eosinophil counts were strikingly suppressed. In this regard, both recombinant and endog- enous interferon- $\alpha$ have been shown to inhibit antigeninduced eosinophil infiltration of the trachea in sensitized mice [32]. Recently, an interferon- $\alpha$ receptor on eosinophils has been described [33], and interferon- $\alpha$ can inhibit the release of several eosinophil mediators including IL-5. In IL-5 deficient mice, the normal airway eosinophilia and hyperresponsiveness seen after aerosol challenge with ovalbumin is eliminated [34]. Additionally, recombinant interferon- $\alpha$ selectively inhibits the production of IL- 5 by CD4+ T cells [35]. Thus, the alterations noted in airway inflammation and physiology following imiquimod treatment could be related to the effects that interferon- $\alpha$ may have had on diminishing IL-5 levels within the airway, regardless of the presence or absence of a concomitant viral infection.

Rats typically exhibit a transient loss of weight during acute viral illness, presumably due to cytokine-mediated decreases in food and water intake. Imiquimod also had an apparent anorexic effect in rats that resulted in weight loss on the day of dosing, but normal growth thereafter. This pattern of decreased water intake and transient interruption of weight gain has been seen in guinea-pigs treated with imiquimod [6]. This observation is consistent both with the transient elevation of serum interferon- $\alpha$ after imiquimod dosing and with anorexia, fatigue, fever, and headache reported by human subjects treated orally with imiquimod [17]. Interestingly, imiquimod treatment completely prevented the virus-associated weight loss in the current study.

The results of these studies in rats suggest that treatment with imiquimod could potentially modulate the development of airway inflammation and dysfunction during acute viral respiratory infection in humans. Although the precise biological, immunological, and physiological targets influenced by imiquimod in vivo are still unknown, our results indicate that this compound clearly possesses pharmacological properties that warrant further study and characterization in the development of specific therapeutic modalities for the treatment and/or prevention of virus-induced asthma.

\section{References}

1. Pattemore PK, Johnston SL, Bardin PG. Viruses as precipitants of asthma symptoms. I. Epidemiology. Clin Exp Allergy 1992; 22: 325-336.

2. Cypcar D, Stark J, Lemanske RF Jr. The impact of respiratory infections on asthma. Pediatr Clin N Amer 1992; 39: 1259-1276.

3. Bellanti JA, Kadlec JV, Escobar-Gutierrez A. Cytokines and the immune response. Pediatr Clin N Amer 1994; 41: 597-621.

4. Bernstein DI, Harrison CJ. Effects of the immunomodulating agent R-837 on acute and latent herpes simplex virus type 2 infections. Antimicrob Agents Chemother 1989; 33: 1511-1515.

5. Harrison CJ, Miller RL, Bernstein DI. Posttherapy suppression of genital herpes simplex virus (HSV) recurrences and enhancement of HSV-specific T-cell memory by imiquimod in guinea pigs. Antimicrob Agents Chemother 1994; 38: 2059-2064.

6. Harrison CJ, Jenski L, Voychehovski T, Bernstein DI. Modification of immunological responses and clinical 
disease during topical R-837 treatment of genital HSV-2 infection. Antiviral Res 1988; 10: 209-224.

7. Bernstein DI, Miller RL, Harrison CJ. Effects of therapy with an immunomodulator (imiquimod, R-837) alone and with acyclovir on genital HSV-2 infection in guinea-pigs when begun after lesion development. Antiviral Res 1993; 20: $45-55$.

8. Chen M, Griffith BP, Lucia HL, Hsiung GD. Efficacy of S26308 against guinea-pig cytomegalovirus infection. Antimicrob Agents Chemother 1988; 32: 678-683.

9. Kende M, Lupton HW, Canonico PG. Treatment of experimental viral infarctions with immunomodulators. Adv Biosc 1988; 68: 51-63.

10. Sidky YA, Borden EC, Weeks CE, Reiter MJ, Hatcher JF, Bryan GT. Inhibition of murine tumor growth by an interferon-inducing imidazoquinolinamine. Cancer Res 1992; 52: 3528-3533.

11. Weeks CE, Gibson SJ. Induction of interferon and other cytokines by imiquimod and its hydroxylated metabolise $\mathrm{R}-842$ in human blood cells in vitro. $J$ Interferon Res 1994; 14: 81-85.

12. Megyeri K, Au W, Rosztoczy I, et al. Stimulation of interferon and cytokine gene expression by imiquimod and stimulation by sendai virus utilize similar signal transduction pathways. Mol Cell Biol 1995; 15: 2207-2218.

13. Reiter MJ, Testerman TL, Miller RL, Weeks CE, Tomai MA. Cytokine induction in mice by the immunomodulator imiquimod. J Leukoc Biol 1994; 55: 234-240.

14. Gibson SJ, Imbertson LM, Wagner TL, et al. Cellular requirements for cytokine production in response to the immunomodulators imiquimod and S-27609. J Interferon Cytokine Res 1995; 15: 537-545.

15. Testerman TL, Gerster JF, Imbertson LM, et al. Cytokine induction by the immunomodulators imiquimod and S27609. J Leukoc Biol 1995; 58: 365-372.

16. Gibson SJ, Elrod SV, Miller RL, Weeks CE. Oral R-837 induces alpha interferon in cynomolgus monkeys. J Interferon Res 1990; 10: S124.

17. Witt PL, Ritch PS, Reding D, et al. Phase I trial of an oral immunomodulator and interferon inducer in cancer patients. Cancer Res 1993; 53: 5176-5180.

18. Castleman WL, Brundage-Anguish LJ, Kreitzer L, Neuenschwander SB. Pathogenesis or bronchiolitis and pneumonia induced in neonatal and weanling rats by parainfluenza (sendai) virus. Am J Pathol 1987; 129: 277286.

19. Sorkness R, Clough JJ, Castleman WL, Lemanske RF Jr. Virus-induced airway obstruction and parasympathetic hyperresponsiveness in adult rats. Am J Respir Crit Care Med 1994; 150: 28-34.

20. Sorkness R, Lemanske RF Jr, Castleman WL. Persistent airway hyperresponsiveness after neonatal viral bronchiolitis in rats. J Appl Physiol 1991; 70: 375-383.

21. Sheth KK, Sorkness RL, Clough JJ, McAllister PK, Castleman WL, Lemanske RF Jr. Reversal of persistent post- bronchiolitis airway abnormalities with dexamethasone in rats. J Appl Physiol 1994; 76: 333-338.

22. Brennan GI, Kronenburg LH. Automated bioassay of interferons in microtest plates. Biotechniques 1983; 1: 78-82.

23. Sorkness R, Lemanske RF Jr. Attenuation of airway hyperresponsiveness during acute viral infection using the 21-aminosteroid U-83836E in rats. Pulm Pharm 1996; 9: 219-222.

24. Varner AK, Sorkness RL, Kumar A, et al. Effects of Imiquimod on post-viral asthma-like syndrome in BN rats. $J$ Allergy Clin Immunol 1997; 99: S127.

25. Miller RL, Birmachu W, Gerster JF, et al. Imiquimod: cytokine induction and antiviral activity. International Antiviral News 1995; 3: 111.

26. Romagnani S. Regulation of the development of type 2 T-helper cells in allergy. Curr Opinion Immunol 1994; 6: 838-846.

27. Brinkmann V, Geigar T, Alkan S, Heusser CH. Interferon alpha increases the frequency of interferon gamma-producing human CD4+ T cells. J Exp Med 1993; 178: 16551663.

28. Parronchi P, De Carli M, Manetti R, et al. IL-4 and IFN (alpha and gamma) exert opposite regulatory effects on development of cytolytic potential by Th1 or Th2 human T cell clones. J Immunol 1992; 149: 2977-2983.

29. Finkelman FD, Svetic A, Gresser I, et al. Regulation by interferon a of immunoglobulin isotype selection and lymphokine production in mice. J Exp Med 1991; 174: 1179_ 1188.

30. Tang Y, Graham BS. Anti-IL-4 treatment at immunization modulates cytokine expression, reduces illness, and increases cytotoxic T-lymphocyte activity in mice challenged with respiratory syncytial virus. J Clin Invest 1994; 94: 1953-1958.

31. Glyllenhammar H, Hafstrom I, Ringertz B, Uden A, Palmblad J. Recombinant human leukocyte interferon modulates neutrophil function in vitro. $J$ Interferon Res 1988; 8: 441-449.

32. Nakajima H, Nakao A, Watanabe Y, Yoshida S, Iwamoto I. IFN- $\alpha$ inhibits antigen-induced eosinophils and CD4+ T-cell recruitment into tissue. J Immunol 1994; 153: 1264 1270.

33. Aldebert D, Lamkioued B, Desaint C, et al. Eosinophils express a functional receptor for interferon a: Inhibitory role of interferon a on the release of mediators. Blood 1996; 87: 2354-2360.

34. Foster PS, Hogan SP, Ramsay AJ, Matthaei KI, Young IG. Interleukin 5 deficiency abolishes eosinophilia, airways hyperreactivity, and lung damage in a mouse asthma model. J Exp Med 1996; 183: 195-201.

35. Schandene L, Del Prete GF, Cogan E, et al. Recombinant interferon-alpha selectively inhibits the production of interleukin- 5 by human CD4+ T cells. J Clin Invest 1996; 97: 309-315. 